\title{
Cambalache: ¡No somos buitres!
}

\author{
L Henry MONCRIEF \\ Universidad Central de Venezuela, Caracas, Distrito Capital, Venezuela
}

DOI 10.11606/issn.2316-9133.v25i25p333-341

Cambalache tiene dos acepciones: es el nombre del vertedero de Ciudad Guayana (Norte de Venezuela), el polo industrial más importante del sur de Venezuela; y es el nombre de una comunidad indígena de recuperadores de desechos. Normalmente, la primera vuelve invisible la segunda, la ciudad imagina un lugar inhabitado y putrefacto donde se deposita su basura. La realidad consiste en que cientos de familias viven de estos desechos, una economía subterránea donde las mujeres indígenas Warao buscan la manera de subsistir.

Ante una imagen fragilizada por los estereotipos sociales y la estigmatización, "No somos buitres" es la consigna con la que reclaman su humanidad las trabajadoras de Cambalache. Dicha frase resume la indignación del pueblo Warao, una primera conciencia de su exclusión social, del detrimento de sus derechos humanos y una reivindicación cultural de la imagen propia. Este posicionamiento es reciente, significa un reclamo al Estado venezolano para demandar mejores condiciones de trabajo, salud, atención sanitaria, educativa y humanitaria.

El ensayo fotográfico realizado en 2014 en el marco del trabajo antropológico del autor intenta desplegar el mencionado reclamo de dignidad moral a través del punto de vista de los afectados. Así, la rudeza del oficio en la basura tiene otra cara, aparece la vida cotidiana con su rostro humano, sus sufrimientos, consuelos y alegrías. Cambalache no es únicamente el escenario brutal del vertedero, de hecho sus habitantes lo desmienten, lo desmontan y lo transforman cada día. La cultura femenina indígena es soporte moral de esta situación: la maternidad, la solidaridad y el entorno fluvial son elementos que afirman esta resistencia psicológica a la miseria material. De esta manera, el documental pretende un ensayo de "fotografía de dignificación"; un compromiso autoral por interpretar la "voz visual" del Otro, del indígena excluido y marginado por una situación social que lo rebasa: ser recuperador de basura en una gran ciudad.

autor Henry Moncrieff

Antropólogo social de la Universidad Central de Venezuela. Maestría en Ciencias Sociales de la Universidad Autónoma del Estado de Morelos. 


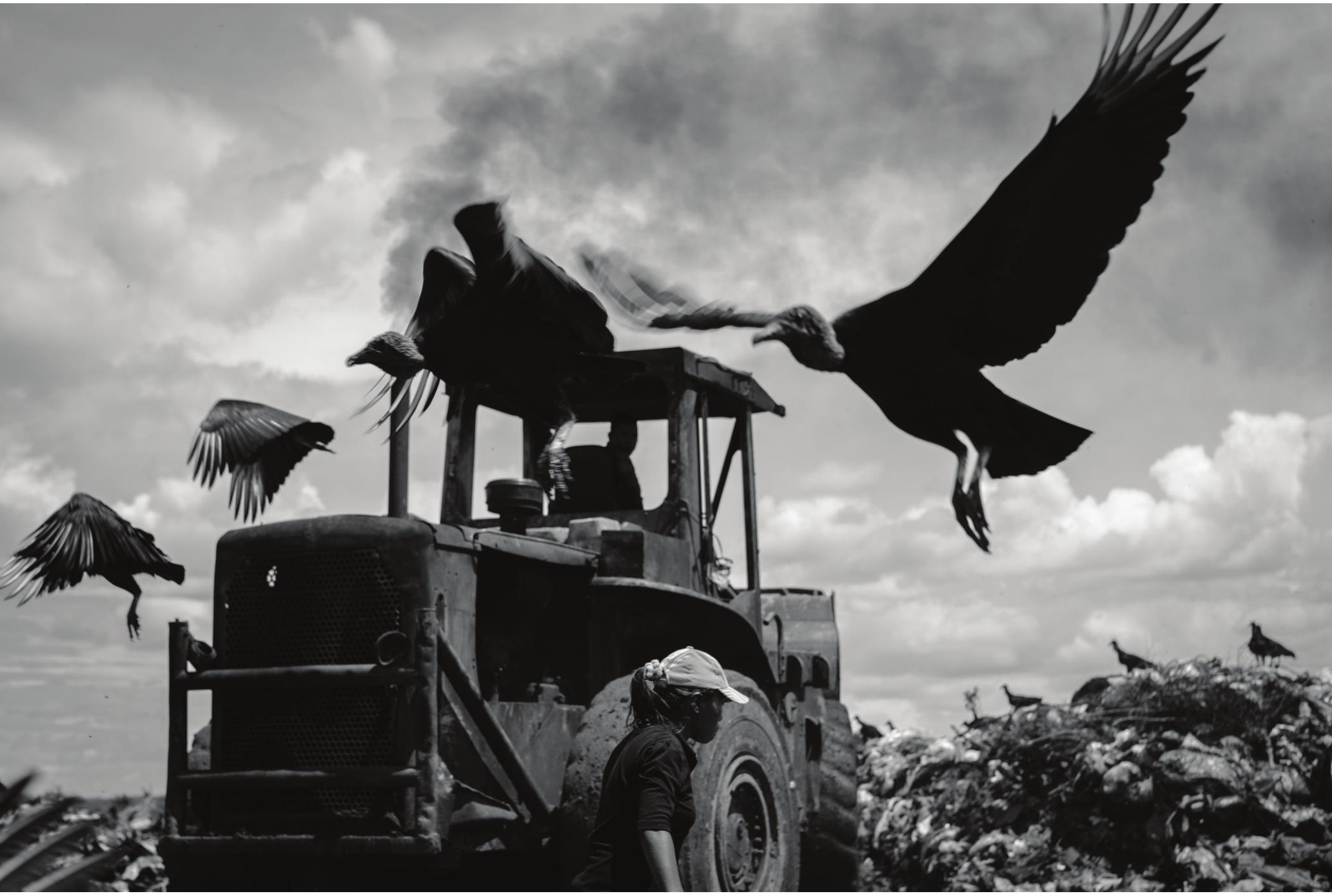

1. Mujer camina debajo de los buitres en el vertedero 
CAmbalache: ;No somos buitres! | 335

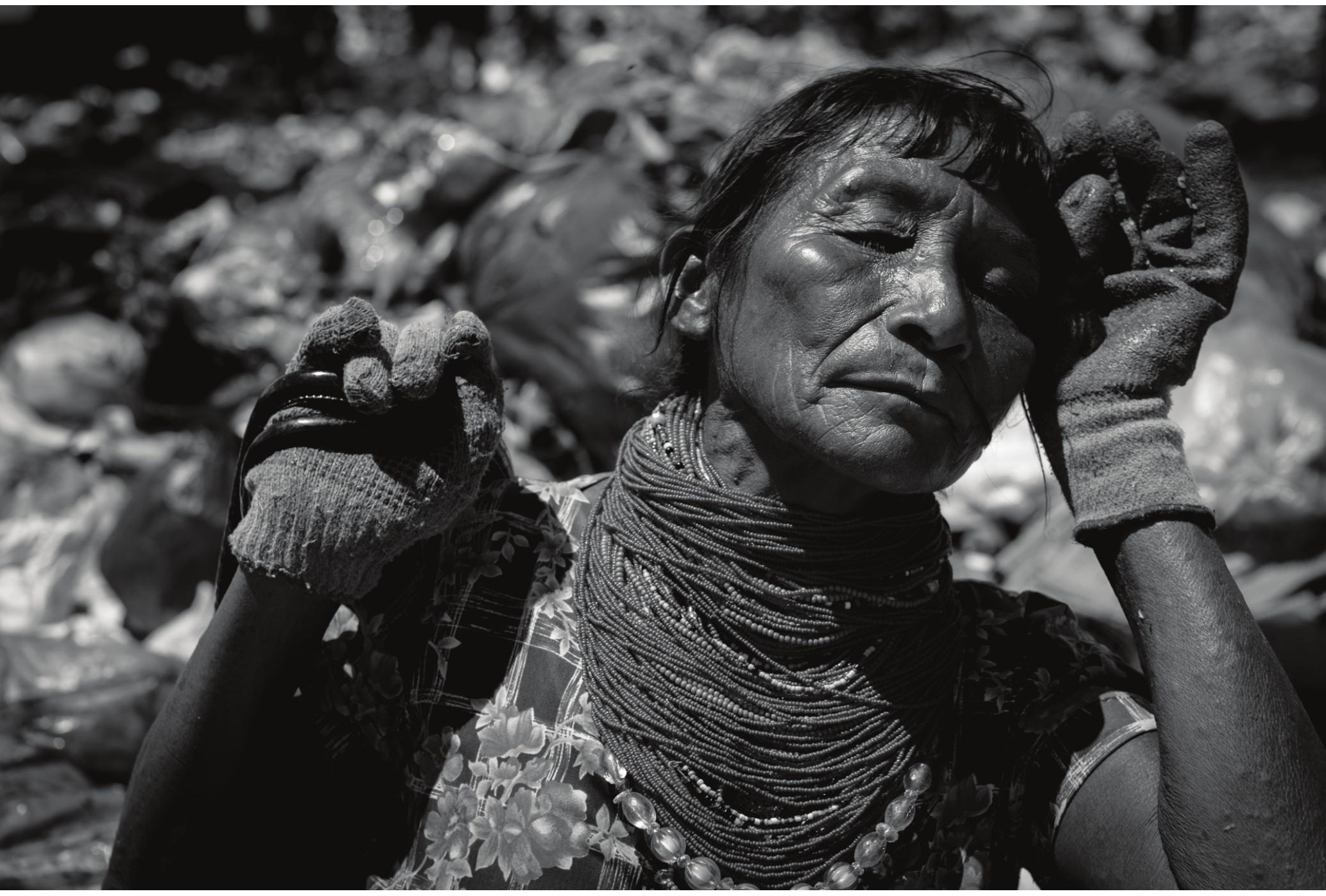

2. Mujer anciana en las altas temperaturas del vertedero 


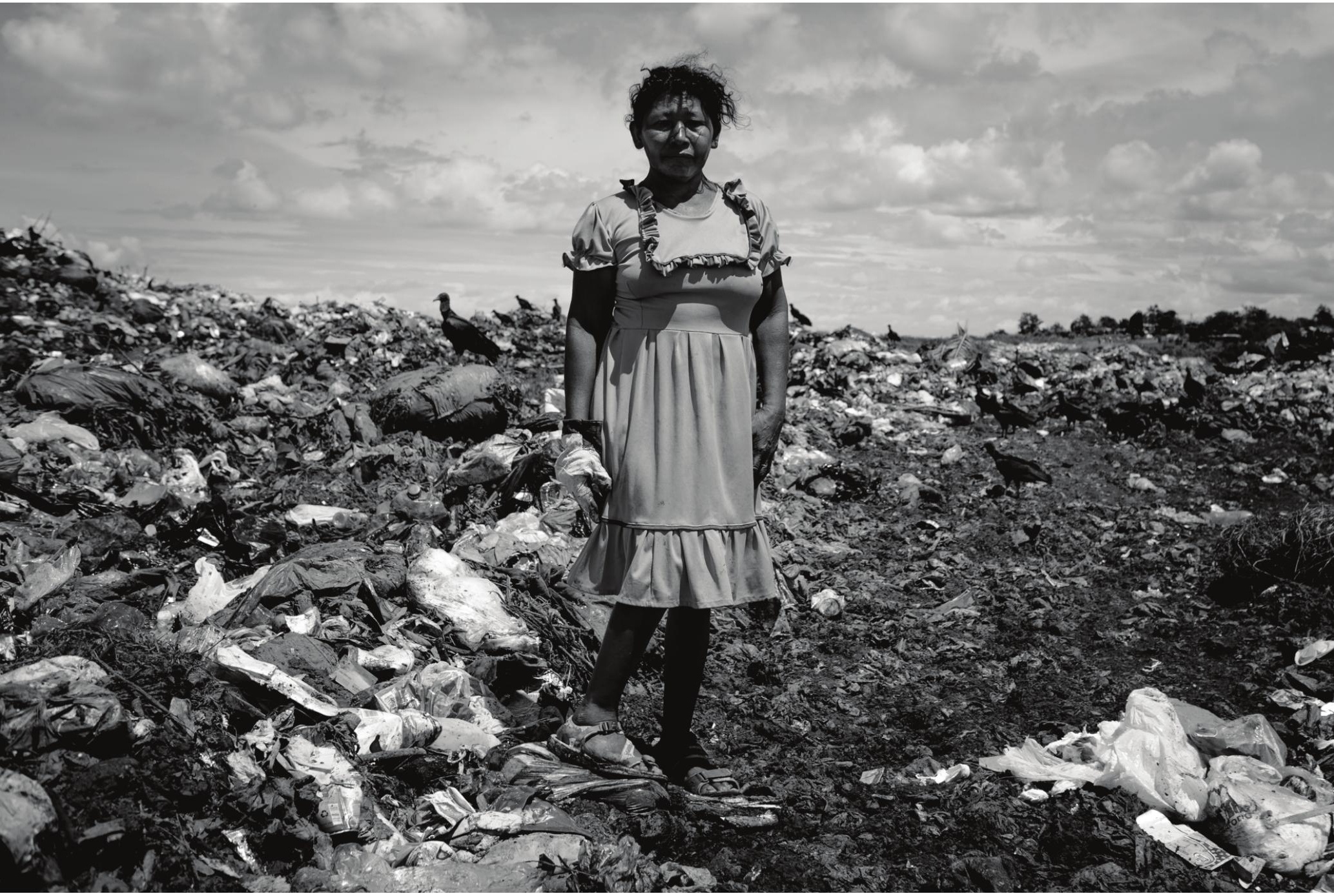

3. Mujer con traje tradicional indígena en el vertedero 
CAmbalache: ;No somos buitres! | 337

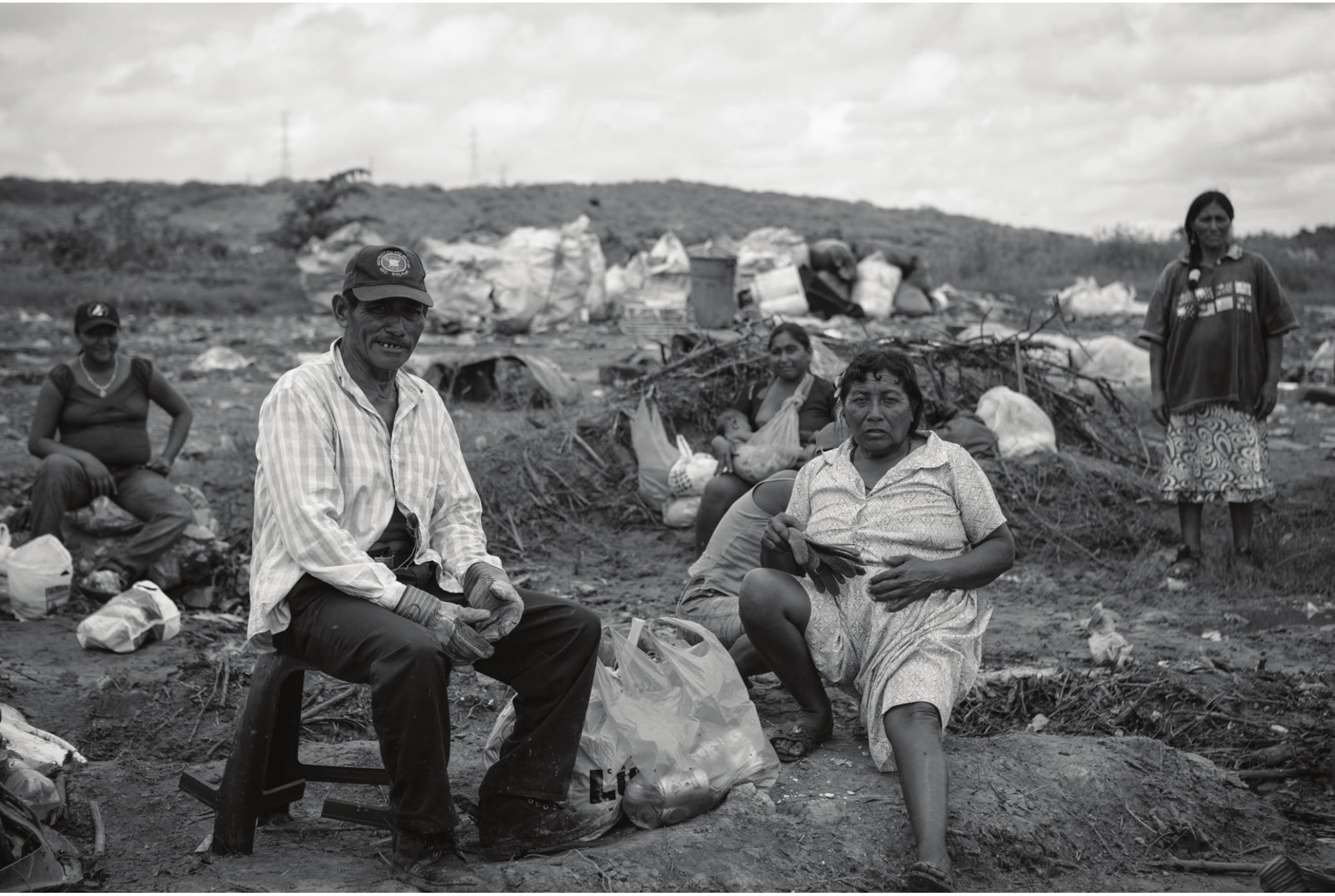

4. Familia indígena en el vertedero 


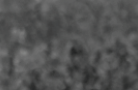


340 | Henry Moncrief

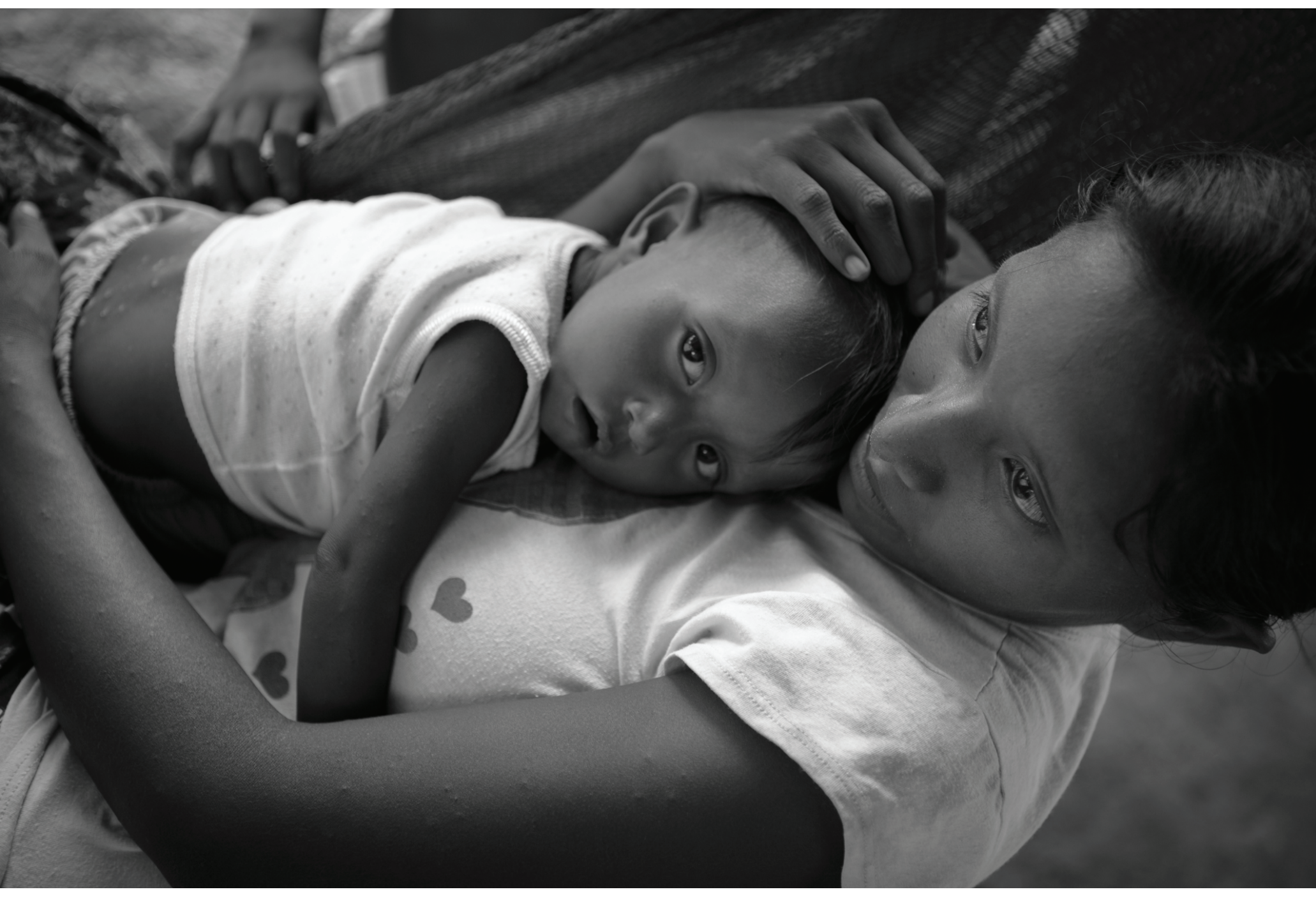

7. Mujer con su hijo en hamaca 


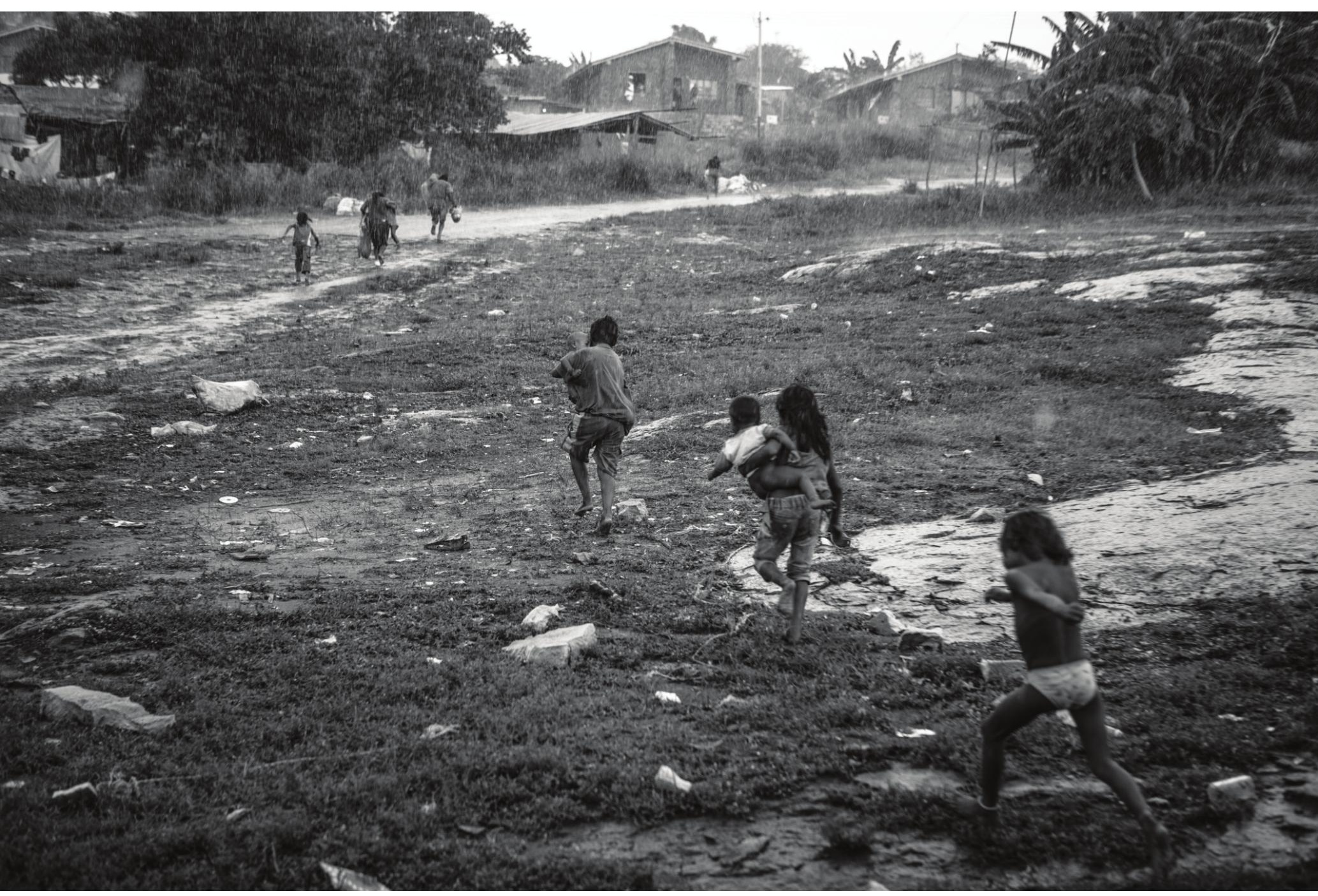

8. Jóvenes corriendo bajo la lluvia 